\title{
Knowledge and Practice Regarding Periodontal Health / Disease and Oral Hygiene among Medical, Ayurveda and Homeopathy Undergraduate Students of Yenepoya University, Mangalore - A Cross Sectional Study
}

\author{
Raghavendra U. ${ }^{1}$, Vijaya Kumar², Anupama Rao ${ }^{3}$, Rajesh Shankar Kashyap4, \\ Subramaniam M. Rao ${ }^{5}$, Vinita Boloor ${ }^{6}$, Seema Patil ${ }^{7}$
}

\begin{abstract}
${ }^{1}$ Department of Biochemistry, Yenepoya Medical College, Yenepoya University, Mangalore, Karnataka, India. 2, 3, 4, 6 Department of Periodontology, Yenepoya Dental College, Yenepoya University, Mangalore, Karnataka, India.

${ }^{5}$ Department of Periodontology, PMNM Dental College and Hospital, Bagalkot, Karnataka, India.

${ }^{7}$ Department of Statistics, Yenepoya University, Mangalore, Karnataka, India.
\end{abstract}

\section{ABSTRACT}

\section{BACKGROUND}

The attitude towards oral health reflects the overall health. Knowledge of health care professionals and their attitudes toward oral care corresponds to their understanding of the importance of preventive dental procedure and improving the oral health of patients. We wanted to assess the knowledge and practice regarding periodontal health / disease and oral hygiene among medical, ayurveda and homeopathy undergraduate students of Yenepoya (Deemed to Be University) (YU) and also determine their attitude and awareness towards oral health.

\section{METHODS}

The data related to their knowledge and practice towards the oral health was assembled using a self administered, validated questionnaire containing 13 questions which had multiple choice answers. The questionnaire was distributed through Google form among 341 medical, ayurveda and homeopathy undergraduate students of YU aged more than 17 years.

\section{RESULTS}

Survey responses were downloaded onto Google sheets and the data collected were coded, entered in Microsoft Excel and analysed using SPSS version 23 (Chicago, USA). Majority of study participants in different colleges showed lack of knowledge and practice regarding oral hygiene practices. To compare the mean scores of three colleges under YU for knowledge based and practice questions, ANOVA was performed. There was no significant difference found in knowledge and practice towards oral hygiene among medical, ayurveda and homeopathy colleges of YU. P < 0.05 was considered as statistically significant.

\section{CONCLUSIONS}

Professional health care students who will be the future backbone of the community health care have limited knowledge on periodontal disease and oral hygiene practices. There is no difference in knowledge and practices regarding oral hygiene among the students of medical, ayurveda and homeopathy colleges of YU. It highlights the need of incorporating oral health education in University curriculum for non dental students during their study period.

\section{KEY WORDS}

Knowledge, Practice, Periodontal Disease, Oral Hygiene Practices, Non-Dental Students, Oral Health Education
Corresponding Author:

Dr. Anupama Rao,

Department of Periodontology,

Yenepoya Dental College,

Yenepoya University, Deralakatte,

Mangalore - 575018,

Karnataka, India.

E-mail: dranuperio@gmail.com

DOI: $10.14260 / j e m d s / 2021 / 409$

How to Cite This Article:

Raghavendra U, Kumar V, Rao A, et al. Knowledge and practice regarding periodontal health / disease and oral hygiene among medical, ayurveda and homeopathy undergraduate students of Yenepoya University, Mangalore - a cross sectional study. J Evolution Med Dent Sci 2021;10(27):1996-2000, 10.14260/jemds/2021/409

Submission 02-02-2021, Peer Review 06-05-2021, Acceptance 13-05-2021, Published 05-07-2021.

Copyright (C) 2021 Raghavendra U. et al. This is an open access article distributed under Creative Commons Attribution License [Attribution 4.0 International (CC BY 4.0)] 


\section{BACKGROUND}

Oral health is a paramount aspect of general health that can be defined as "a standard of health of the oral and related tissues which enables an individual to eat, speak, and socialize without active disease, discomfort or embarrassment and which contributes to general well being". Periodontal disease is one of the most prevalent diseases affecting $20-50 \%$ of global population. ${ }^{1}$ It is the main reason for tooth loss, and also considered as a threat to oral health. ${ }^{2}$ The attitude towards oral health dictates the general health status of an individual. ${ }^{3}$ As periodontal diseases are linked to many systemic diseases, health practitioners around the world play an important role in identifying the disease at the earliest and limiting its proportion. ${ }^{4}$ The successful management of periodontal disease in general population depends upon knowledge of preventive measures, early identification of symptoms and effective treatment. 5 Tooth loss due to periodontal and other dental diseases can have severe impact on an individual's overall well being. Developing countries such as India, have lots of dental related myths which prevent major part of uneducated population of the society in seeking adequate dental treatment on right time, hence losing most of their dentition in early phases of life. This can be prevented through awareness and education on oral health by dental and nondental health care professionals in society. Lack of awareness on oral hygiene practices among general population has become a major social problem. As lot of importance is now being given on preventive aspects than the treatment itself, it is justified to give due preferences to preventive strategies which will reduce oral disease burden and help in maintaining good dentition. Such preventive approaches would also be helpful in inculcating positive attitude towards oral health maintenance among the general public.

In India, most of the patients in the first instance, consult non dental health professionals (Medical, Ayurveda, Homeopathic) even for their oral health problems. Well informed health care professionals can be instrumental in guiding and referring patients with oral health care needs to dental professionals. ${ }^{6}$ Thereby, in an attempt to improve the oral health of general population, it is paramount to understand the existing knowledge of undergraduate students regarding preventive oral care and oral hygiene practice health care. Guidance by health professionals help most of the general public seeking dental care on right time.

There is a general opinion that health professionals are more familiar with interrelationship between oral and overall general health, but sparse data is available in this context in literature. ${ }^{7}$ Scientific literature till date mentions only few studies exploring the existing knowledge deficit with respect to periodontal health and oral hygiene among non dental health professional undergraduate students.8,9 Even studies comparing stand alone university non dental health professional student population are relatively sparse..$^{10}$ There was significant gap noticed in literature regarding assessment of oral health knowledge and practice among non dental health professional students studying in standalone university campus. In the above context, a cross sectional study was conducted to assess and compare the knowledge and practice regarding periodontal health and oral hygiene among medical, ayurveda and homeopathy undergraduate students of YU who will be the part of health care system of India in future.

\section{METHODS}

A descriptive, cross sectional study was conducted on undergraduate students of Medical, Ayurveda and Homeopathy colleges under YU. The study was conducted between $26-11-2019$ and $11-01-2020$.

\section{Study Population and Sample Size}

Total of 321 undergraduate students of medical, ayurveda and homeopathy colleges under YU aged 18 or more were selected after obtaining written informed consent. Participants consisted of first year to third year students of respective courses. Random sampling technique using computer generated numbers was employed in selection of study participants. Sample size calculation for estimation of proportion was done by formula $\mathrm{N}=\mathrm{z}^{2} \mathrm{pq} \div \mathrm{d}^{2}$.

At $5 \%$ level of significance with $66 \%$ estimated proportion and $9 \%$ margin of error ${ }^{9}$ the total sample size of $\mathrm{N}$ $=107$ was decided for each of the three groups. Total responses received through Google forms were 341 (Fig. 1)

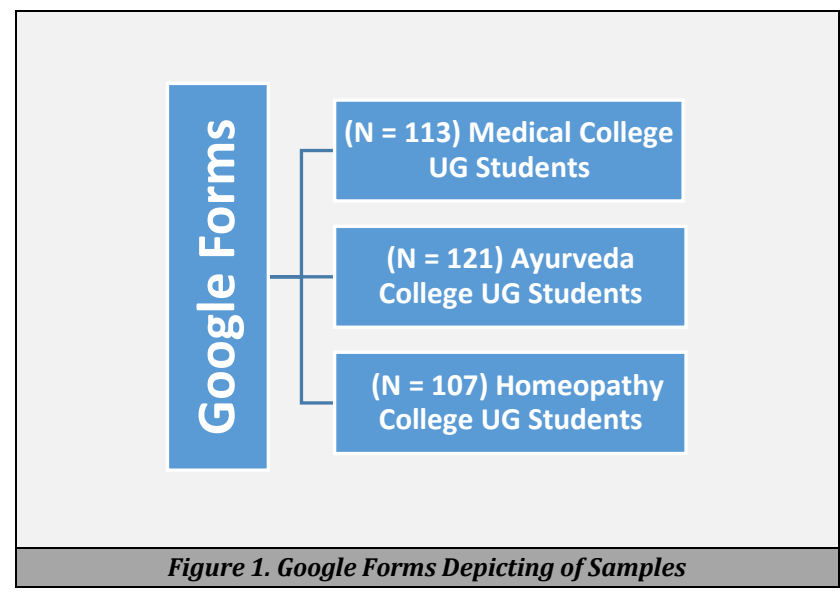

\section{Ethical Clearance}

Ethical clearance was obtained from the YU Ethics Committee (YEC - 1 / 2019 / 209) before starting the study.

A web-based, Self reported, structured, validated and published questionnaire ${ }^{9}$ about knowledge and practice regarding periodontal disease and oral hygiene was distributed through Google forms to eligible undergraduate students of medical, ayurveda and homeopathy colleges under YU. Survey forms were distributed to all the study participants through Whatsapp, Instagram social media platform. Questionnaires were divided in two sections. First section included demographics - age, gender, professional course details. Second section of questionnaire comprised of 15 questions focused on the awareness and practice on preventive and therapeutic approaches related to periodontal health and disease. Each question had only one correct answer and it was scored as +1 . Incorrect answer was given the score of zero. Survey responses were collected during the above mentioned study period. 
Age - Gender - Student - Medical / Ayurveda / Homeopathy

Do you brush your teeth?

a) Yes b) No

If yes, How often do you brush your teeth

a)Usually once daily b) Usually twice daily

c)Usually thrice daily d) Occasionally

How often should you change your tooth brush?

a) 6 months b) 3 months

c) 1 year d) Till bristle gets frayed

Which type of brushing technique is better for good oral health

a) Horizontal stroke b) vertical stroke

c) Roll stroke d) Not aware

Do you use dental floss?

a) Yes b) No

If Yes, how often do you use?

a) Every day b) Occasionally

How often do you use antimicrobial mouthwash

A)Never b) Daily

c) Once a week d) As recommended by the dentist

What is the commonest cause of bleeding gums?

a) Vitamin C deficiency b) Gum disease

c) Injury to gums d) not aware

What is commonest cause of bad breath?

a) Smoking b) Poor oral hygiene

c) Lung disease d) Intake of an odoriferous food items

Do you think coffee / tea causes staining of teeth

a) Yes b) No c) May be d) Not aware

What do you think is the most commonest cause for loose teeth?

a) Old age b) Gum disease

c) Accident / injury d) Nail biting habit

Do you think sensitivity to hot or cold food can be treated

a) Yes b) No c) May be d) Not aware

Do you think bad oral hygiene affects your general health

a) Yes b) No c) May be d) Not aware

What is the commonest cause for receding gums?

a) Improper tooth brushing b) Nail biting

c) Injury d) Gum disease

How often you visit your dentist for cleaning your teeth

a) In 3 months b) In 6 months

c) Once in a year d) Never till now

Figure 2. Proforma of Questionnaire ${ }^{9}$

\section{Statistical Analysis}

Survey responses were downloaded into Google sheets and the data collected were coded, entered in Microsoft Excel and analyzed using SPSS version 23 (Chicago, USA). Descriptive statistics, including mean, standard deviation was calculated. To compare the mean scores of three colleges for knowledge based and Practice questions, ANOVA was performed. $\mathrm{P}<0.05$ was considered as statistically significant.

\section{RESULTS}

Out of 341 participants, 78 (22.87\%) were males, and 263 $(77.13 \%)$ were females. The mean age of the students was $20.48 \pm 1.63$ years with minimum age of 18 years and maximum age of 25 years. (Table 1 )

\begin{tabular}{|cc|}
\hline Demographics & Mean (SD) \\
Age & $20.48(1.63)$ \\
Gender & Percentage \\
Male & $78(22.87 \%)$ \\
Female & $263(77.13 \%)$ \\
\hline Table 1. Socio-Demographic Characteristics \\
\hline
\end{tabular}

\begin{tabular}{|c|c|c|c|c|}
\hline \multicolumn{2}{|c|}{ Knowledge based Questions } & $\begin{array}{l}\text { Medical } \\
\text { College }\end{array}$ & $\begin{array}{l}\text { Ayurvedic } \\
\text { College }\end{array}$ & $\begin{array}{c}\text { Homeopathy } \\
\text { College }\end{array}$ \\
\hline \multirow{2}{*}{$\begin{array}{l}\text { Brushing } \\
\text { technique }\end{array}$} & Correct answer & $34(10 \%)$ & $41(12.1 \%)$ & $30(8.8 \%)$ \\
\hline & Wrong answer & $78(23 \%)$ & $80(23.6 \%)$ & $76(22.4 \%)$ \\
\hline \multirow{2}{*}{ Bleeding gums } & Correct answer & $23(6.8 \%)$ & $35(10.3 \%)$ & $18(5.3 \%)$ \\
\hline & Wro & $89(26.3 \%)$ & $86(25.4 \%)$ & $88(26 \%)$ \\
\hline \multirow{2}{*}{ Receding gum } & Correct answer & $27(8 \%)$ & $37(10.9 \%)$ & $32(9.4 \%)$ \\
\hline & Wrong answer & $85(25.1 \%)$ & $84(24.8 \%)$ & $74(21.8 \%)$ \\
\hline \multirow{2}{*}{ Bad breath } & & $80(23.6 \%)$ & $100(29.5 \%)$ & $81(23.9 \%)$ \\
\hline & & 32( & & \\
\hline \multirow{2}{*}{ Stains } & Correct answer & $58(17.1 \%)$ & 46 (13.6\%) & $44(13 \%)$ \\
\hline & Wrong answer & $54(15.9 \%)$ & $75(22.1 \%)$ & $62(18.3 \%)$ \\
\hline \multirow{2}{*}{ Loose teeth } & Cor & $74(2$ & $80(23.6 \%)$ & 64 \\
\hline & $\mathrm{Wr}$ & $38(1$ & 41( & 42 \\
\hline \multirow{2}{*}{ Sensitivity } & Correct & $70(20.6 \%)$ & $59(17.4 \%)$ & $70(20.6 \%)$ \\
\hline & Wrong answer & $42(12.4 \%)$ & $62(18.3 \%)$ & $36(10.6 \%)$ \\
\hline \multirow{2}{*}{$\begin{array}{l}\text { Oral hygiene and } \\
\text { general health }\end{array}$} & Correct & $97(28.6 \%)$ & $95(28 \%)$ & $87(25.7 \%)$ \\
\hline & Wron & $15(4$ & $4 \%)$ & $19(5.6 \%)$ \\
\hline \multirow{2}{*}{ Recession } & Corre & $64(18.9 \%)$ & $85(25.1 \%)$ & 77 (22.7\%) \\
\hline & Wrong answer & $48(14.2 \%)$ & $36(10.6 \%)$ & $29(8.6 \%)$ \\
\hline \multicolumn{5}{|c|}{$\begin{array}{c}\text { Table 2. Descriptive Statistics for Various Knowledge Based } \\
\text { Items in the Questionnaire }\end{array}$} \\
\hline
\end{tabular}

\begin{tabular}{|c|c|c|c|c|}
\hline \multicolumn{2}{|c|}{ Practice Based Questions } & $\begin{array}{l}\text { Medical } \\
\text { College }\end{array}$ & $\begin{array}{l}\text { Ayurvedic } \\
\text { College }\end{array}$ & $\begin{array}{c}\text { Homeopathy } \\
\text { College }\end{array}$ \\
\hline \multirow{2}{*}{ Do you brush } & Cor & $112(33 \%)$ & $121(35.7 \%)$ & $103(30.4 \%)$ \\
\hline & & & & \\
\hline \multirow{2}{*}{$\begin{array}{c}\text { How often do you } \\
\text { brush }\end{array}$} & & 50 & & \\
\hline & & & & \\
\hline \multirow{2}{*}{ Use of dental floss } & Corr & $2 \%)$ & 15 & \\
\hline & & $91(2$ & 106( & $\%)$ \\
\hline \multirow{2}{*}{$\begin{array}{c}\text { How often do you } \\
\text { use? }\end{array}$} & & & & \\
\hline & & 105 & 119 & \\
\hline \multirow{2}{*}{$\begin{array}{l}\text { Use antimicrobial } \\
\text { mouthwash }\end{array}$} & Corr & $27 i$ & 37( & 2( \\
\hline & Wro & 85 ( $25.1 \%)$ & 84( & 74( \\
\hline \multirow{2}{*}{ Visit to dentist } & & & & \\
\hline & & 97( & 111 & \\
\hline \multirow{2}{*}{$\begin{array}{l}\text { Replacement of } \\
\text { toothbrush? }\end{array}$} & & $21(6.2 \%)$ & $20(5.9 \%)$ & $5.6 \%)$ \\
\hline & Wrong answer & $91(26.8 \%)$ & $101(29.8 \%)$ & $87(25.7 \%)$ \\
\hline \multicolumn{5}{|c|}{$\begin{array}{l}\text { Table 2. Descriptive Statistics for Various } \\
\text { Practice Based Items in the Questionnaire }\end{array}$} \\
\hline
\end{tabular}

\begin{tabular}{|c|c|c|c|c|}
\hline Questions & $\begin{array}{l}\text { Students from } \\
\text { Constituent } \\
\text { Colleges }\end{array}$ & Mean (SD) & P Value & $95 \%$ CI \\
\hline \multirow{3}{*}{$\begin{array}{l}\text { Knowledge regarding } \\
\text { oral hygiene and } \\
\text { periodontal disease }\end{array}$} & Medical & $1.53(0.12)$ & \multirow{3}{*}{0.68} & \multirow{3}{*}{1.51 to -1.76} \\
\hline & Ayurveda & $1.52(0.11)$ & & \\
\hline & Homeopathy & $1.51(0.13)$ & & \\
\hline \multirow{3}{*}{$\begin{array}{l}\text { Practice regarding oral } \\
\text { hygiene }\end{array}$} & Medical & $1.76(0.43)$ & \multirow{3}{*}{0.48} & \multirow{3}{*}{1.28 to -1.81} \\
\hline & Ayurveda & $1.69(0.46)$ & & \\
\hline & Homeopathy & $1.70(0.46)$ & & \\
\hline
\end{tabular}


Descriptive statistics for various items in the questionnaire regarding knowledge and practice among medical, ayurveda and homeopathy students has been shown in Table 2. Majority of study participants in all different colleges of YU showed lack of knowledge and practice regarding oral hygiene practices. To compare the mean scores of three colleges for knowledge based and practice questions, ANOVA was performed. (Table 3). The mean score of knowledge and practice was not statistically significant in all three different colleges of YU (Medical, Ayurveda and Homeopathy).

\section{DISCUSSION}

Oral hygiene is the most neglected and ignored practice in India and its non maintenance is directly linked to increased incidence of dental caries and periodontal disease. General population at large, in India, consult medical, ayurveda, and homeopathy health professionals even for their oral health problems. Elhassan $\mathrm{AT}^{11}$ et al. emphasized the crucial role of healthcare providers in identifying the patients with periodontal diseases. Thereby, it is the health professional's duty to spread awareness on regular dental care and direct their patients to visit dental professionals to receive appropriate dental care.

In our present study we found that majority of students of Medical colleges brush their teeth on a regular basis only once daily whereas $66 \%$ students of Ayurveda and $54 \%$ of homeopathy students brushed twice daily regularly. Our findings are in agreement with previous study by $\mathrm{Al}$ Batayneh ${ }^{10}$ who reported high percentage of non dental students brushing regularly only once daily. Based on the findings of current study only 30 to $40 \%$ students of total study population brushed their teeth in roll stroke and only 10 to $20 \%$ replaced their brush every 3 months irrespective of their study course. Knowledge regarding use of dental floss in maintaining oral hygiene in interproximal areas showed very poor response, use of dental floss showed only $7 \%$ of medical, $2 \%$ of ayurveda and $8 \%$ of homeopathy students actually practicing it daily. This finding is consistent with the study of Dayakar et al. ${ }^{9}$ which reported that only $9 \%$ of health professionals were actually aware of flossing. In contrast, study by Hamilton and Coulby in 1991 reported around $44 \%$ study population in North eastern Ontario used dental floss. ${ }^{12}$ This may be attributed to educational policies of Canada regarding oral health. Andhare MG et al. ${ }^{13}$ found in their study that oral health attitude, knowledge, and behaviour were high among the dental students as it is a part of their professional education. Students of medical profession comparatively showed poor oral health knowledge. There was lack of exposure in medical faculty regarding oral health in their curriculum.

Knowledge regarding etiology of gingival disease also seems to be poor among the study population of the present study. Most of the participants think Vitamin C deficiency as a main cause for bleeding gums whereas only $23 \%$ of medical, $35 \%$ of ayurveda and $18 \%$ of homeopathy students were aware of gum disease being the leading cause for gingival bleeding. This result is in line with study by Dayakar et al. ${ }^{9}$ in which only $18 \%$ of medical, $36 \%$ of ayurveda, and $18 \%$ of homeopathy students were aware of the common cause of bleeding gums. The probable reason behind knowledge deficit regarding main cause of bleeding gums could be less emphasis on oral health education in their course curriculum.

Present study findings also confirmed the fact that only small population of non dental health professional students actually visited dentist for tooth cleaning every 3 - 6 months. Studies by Behbehani and Shah ${ }^{14}$ Quteish Taani ${ }^{15}$ also confirmed the same. On contrary, study by Sulekha Rathod et al. ${ }^{16}$ reported that health care professionals who visited their dentist regularly, used proper tooth brushing technique and other interdental aids, had less dental problems and good lifestyle as compared to non health care professionals.

On the contrary, a few encouraging facts of the present study population was the knowledge regarding cause for bad breath, loose teeth and recession. Majority of the study participants were aware of periodontal disease being the cause for above mentioned oral problems. Even their knowledge regarding oral-systemic disease link was high. Quite surprisingly above $90 \%$ of all study participants of all the constituent colleges knew the fact that oral health can affect general health.

This finding is as par to study by $\mathrm{Al}$ - Zarea ${ }^{17}$ in contrast Umeizudike KA et al. ${ }^{18}$ study concluded that knowledge of periodontal disease as a risk factor for systemic illnesses among medical residents in Nigeria was inadequate.

Strength of the study was its diverse population within the university campus. We included larger sample size compared to similar previous study articles. ${ }^{9}$ The main limitation of the study could be inability to generalize the study result to the entire population and most of the students who participated were females from constituent colleges. With considerable limitations, our study concludes with the fact that non dental professionals of YU university are having knowledge deficit regarding periodontal health / disease and oral hygiene practices.

There was no difference seen in the knowledge regarding periodontal health / disease and oral hygiene practices among medical, ayurveda and homeopathy undergraduate students. of YU. The present study results suggests that Professional health care students who will be the future backbone of the community health care have limited knowledge on periodontal disease and oral hygiene practices. ${ }^{19}$ Importance should be given to raise the awareness levels regarding the same among non dental health professional students through oral health talks and oral hygiene awareness programs by dental health education unit. The present study also highlights the need to include Oral health education in university curriculums for non- dental students during their study period.

\section{CONCLUSIONS}

Professional health care students who will be the future backbone of the community health care have limited knowledge on periodontal diseases and oral hygiene practices. Education and awareness needs to be created in non dental students during their teaching program. It will motivate the patients to maintain a good oral hygiene and also provides appropriate referrals to dental specialists for adequate dental 
treatment. This will also help us in reducing overall periodontal disease burden of our society in near future.

Data sharing statement provided by the authors is available with the full text of this article at jemds.com.

Financial or other competing interests: None.

Disclosure forms provided by the authors are available with the full text of this article at jemds.com.

We would like to thank the Principals, teaching faculty and undergraduate students of Yenepoya Medical College, Yenepoya Ayurveda College, Yenepoya Homeopathy College, for their kind support.

\section{REFERENCES}

[1] Nazir MA. Prevalence of periodontal disease, its association with systemic diseases and prevention. Int J Health Sci (Qassim) 2017;11(2):72-80.

[2] Benjamin RM. Oral health: the silent epidemic. Public Health Rep 2010;125(2):158-9.

[3] Rathod S, Khan F, Sarda T. Attitude and awareness towards periodontal health among health care and nonhealth care professionals. SRM J Res Dent Sci 2016;7(1):23-6.

[4] Otomo-Corgel J, Pucher JJ, Rethman MP, et al. State of the science: chronic periodontitis and systemic health. J Evid Based Dent Pract 2012;12(3 Suppl):20-8.

[5] Nagarakanti S, Epari V, Athuluru D. Knowledge, attitude and practice of medical doctors towards periodontal disease. J Indian Soc Periodontol 2013;17(1):137-9.

[6] Rajesh H, Boloor V, Rao A, et al. Knowledge of periodontal disease among group of health care professionals in Yenepoya University, Mangalore. J Educ Ethics Dent 2013;3(2):60-5.

[7] Alzammam N, Almalki A. Knowledge and awareness of periodontal diseases among Jordanian University students: a cross-sectional study. J Indian Soc Periodontol 2019;23(6):574-9.

[8] Nagrik A, Bhagat BA. Knowledge awareness and attitude of medical students and teachers towards oral hygiene-a questionnaire study. MedPulse - International Journal of Dentistry 2017;2(1):1-8.
[9] Dayakar MM, Kumar J, Pai GP, et al. A survey about awareness of periodontal health among the students of professional colleges in Dakshina Kannada District. J Indian Soc Periodontol 2016;20(1):67-71.

[10] Al-Batayneh OB, Owais AI, Khader YS. Oral health knowledge and practices among diverse university students with access to free dental care: a cross-sectional study. Open J Stomatol 2014;4(3):135-42.

[11] Elhassan AT, Alfakry H, Peeran SW. Reasons to seek periodontal treatment in a libyan community. Dent Med Res 2017;5(2):38-42.

[12] Hamilton ME, Coulby WM. Oral health knowledge and habits of senior elementary school students. J Public Health Dent 1991;51(4):212-9.

[13] Andhare MG, Dhonge RP, Dhuldhwaj RM, et al. A comparative evaluation of awareness regarding periodontal health and oral hygiene practices among dental and medical undergraduate students in Beed District of Maharashtra. Indian J Dent Sci 2017;9(4):2159.

[14] Behbehani JM, Shah NM. Oral health in Kuwait before the Gulf War. Med Princ Pract 2002;11(Suppl 1):36-43.

[15] Taani DSMQ. Periodontal reasons for tooth extraction in an adult population in Jordan. J Oral Rehabil 2003;30(1):110-2.

[16] Rathod S, Khan F, Sarda T. Attitude and awareness towards periodontal health among health care and nonhealth care professionals. SRM J Res Dent Sci 2016;7(1):23-6.

[17] Al-Zarea BK. Oral health knowledge of periodontal disease among university students. Int J Dent 2013;2013:647397.

[18] Umeizudike KA, Iwuala SO, Ozoh OB, et al. Association between periodontal diseases and systemic illnesses: a survey among internal medicine residents in Nigeria. Saudi Dent J 2016;28(1):24-30.

[19] Rao AS, Kumar V. Halitosis: a mirror of systemic and oral health. IOSR Journal of Dental and Medical Sciences 2013;4(3):7-12. 